\title{
Depression, CTCAE
}

National Cancer Institute

\section{Source}

National Cancer Institute. Depression, CT CAE. NCI Thesaurus. Code C55447.

A disorder characterized by melancholic feelings of grief or unhappiness. 